\title{
Papel de la Fuerza Aérea Colombiana en el DESARrollo de la OPERACión Mutatá en 1989, SObre El CAMPaMento del EJÉrCito Popular de LIBERACIÓN-EPL
}

LuCy Rengifo MoRenO ${ }^{1}$

\section{RESUMEN}

La Operación Mutatá, llevada a cabo en 1989 por las Fuerzas Militares, permitió debilitar al grupo guerrillero Ejército Popular de Liberación -EPL- y que el grupo armado ilegal posteriormente se sentara a negociar un acuerdo de paz con el Gobierno Nacional, se reinsertara a la vida civil y participara en la vida política del país y en acontecimientos tan relevantes como la Asamblea Constituyente de 1991. En la Operación Mutatá participaron de manera conjunta las Fuerzas Militares colombianas y este artículo tiene como objetivo analizar cuál fue la participación de la Fuerza Aérea Colombiana en la misma y entender su relevancia en el éxito de esta tarea, que posteriormente influyó en que se diera la negociación y el Acuerdo de paz entre esa guerrilla y el Gobierno Nacional. En este análisis se tuvieron en cuenta las versiones de la prensa nacional, del Grupo de Memoria Histórica y la entrevista con un oficial de la Fuerza Aérea Colombiana que participó en dicha operación, entre otras fuentes.

Palabras clave: Operación Mutatá, Fuerza Aérea Colombiana, Ejército Popular de Liberación -EPL-, Asamblea Nacional Constituyente, Plan Nacional de Rehabilitación-PNR.

Politóloga de la Universidad de los Andes. 


\section{INTRODUCCIÓN}

En las décadas de los ochenta y noventa se da un recrudecimiento del conflicto armado interno en Colombia y la presencia en varias zonas del país de distintos grupos armados al margen de la ley. En este contexto el rol de las Fuerzas Militares en Colombia y, particularmente, de la Fuerza Aérea Colombiana-FAC-fue importante para garantizar la seguridad de la población en el territorio nacional, a través de operaciones conjuntas de la Fuerza Pública.

En este periodo, varias zonas del país, entre ellas la región de Urabá, estuvieron inmersas en los enfrentamientos armados entre los grupos guerrilleros que hacían presencia en la zona, -como las Fuerzas Armadas Revolucionarias de Colombia- FARC-EP-, el Ejército de Liberación Nacional -ELN-y el Ejército Popular de Liberación -EPL-, así como las Autodefensas Unidas de Colombia-AUC-, los grandes carteles del narcotráfico, y las Fuerzas Militares. Estas últimas intentaban preservar la seguridad en las regiones y liberarlas de la lucha entre los distintos grupos ilegales que buscaban el control de los territorios. Una lucha que estaba generando el desplazamiento forzado de campesinos y otras comunidades -como afrodescendientes e indígenas-, debido a los asesinatos, los secuestros y las extorsiones que llevaban a cabo estas organizaciones ilegales.

El EPL fue uno de los principales actores armados en esta zona y allí tuvo su principal campamento. Las Fuerzas Militares con el apoyo de la Fuerza Aérea Colombiana-FAC-, con el fin de restablecer el orden público y llevar la paz realizaron varias operaciones en la región, una de ellas denominada Operación Mutatá, en el municipio de Puerto Libertador, en el departamento de Córdoba, en 1989. Dicha operación fue clave en el debilitamiento de este grupo armado, lo que posteriormente llevaría a su desmovilización, a la firma de un proceso de paz que contó con la participación de otros grupos guerrilleros, a su reinserción a la vida civil y a la participación en la vida política, como lo hizo en la Asamblea Nacional Constituyente de 1991.

El presente documento aborda las dinámicas del conflicto armado y la guerra en Colombia desde el surgimiento de los principales grupos insurgentes, en particular el EPL, y la presencia de este grupo guerrillero 
en la región de Urabá, como una de sus principales zonas de operación y donde estuvo instalado el Mando Central del EPL. Una zona también de agudos conflictos sociales y una de las más azotadas por la violencia. También se detiene en las políticas de los distintos gobiernos en la búsqueda de la paz y la participación de las Fuerzas Militares, en especial la Fuerza Aérea Colombiana, en operaciones que fueron decisivas para el restablecimiento del orden, la desmovilización, la firma del acuerdo de paz y posterior participación política del EPL en la Constituyente de 1991.

Este trabajo ha realizado una revisión bibliográfica en donde se exploraron publicaciones académicas, de las Fuerzas Militares, archivo de prensa (El Tiempo y el Espectador), y el testimonio del Mayor General Luis Ignacio Barón Casas, quién participó como piloto en las operaciones que adelantó la FAC en la región de Urabá.

Después de esta introducción se presenta un breve contexto histórico del nacimiento y consolidación del EPL; posteriormente se concentra en cómo se dio la Operación Mutatá; luego, un apartado sobre el proceso de paz y la Asamblea Nacional Constituyente, para finalizar con algunas conclusiones.

\section{EL EJÉRCITO POPULAR DE LIBERACIÓN-EPL}

Esta organización guerrillera surgió en 1967, casi paralelamente a la fundación de las Fuerzas Armadas Revolucionarias de Colombia -FARC-, en $1964^{2}$ (Centro Nacional de Memoria HistóricA, 2014) y al Ejército de Liberación Nacional-ELN-, en 1964 (PARdo, 2004). Para entender la aparición del EPL se deben tener en cuenta los cambios que estaba sufriendo el Partido Comunista Colombiano-PCC- en ese momento. Había tenido un camino propio durante las décadas del cuarenta y del cincuenta en donde su dirigencia había decidido una posición política contraria a la lucha insurreccional como vía principal de la revolución (VILlARRAGA, 1994). Sin embargo, la coyuntura política nacional e internacional en la década de los sesenta estaba cambiando rápidamente. En el país, en algunos sectores estudiantiles y campesinos

Las FARC conmemoran su hito fundacional con la Operación Marquetalia (mayo, 1964). Sin embargo, formalmente surgieron con ese nombre entre abril y mayo de 1966, durante la II Conferencia de las Guerrillas del Bloque Sur (CEnTro NaCional de Memoria Histórica 2014). 
había un descontento con las restricciones de participación política en el Frente Nacional -que había empezado a gobernar en 1958-e internacionalmente la Revolución Cubana había despertado un fervor revolucionario (GRUPO DE MEMORIA HISTÓRICA, 2013).

El camino de la lucha armada se despunta a partir del quiebre en la postura dominante del PCC, al cual se acusó de estar aliado con la burguesía nacional supuestamente democrática. Algunos de estos sectores fueron acogiendo las críticas del Partido Comunista Chino a las orientaciones soviéticas. De esta manera, la línea comunista china se fue imponiendo en un sector que fundó el Partido Comunista-Marxista Leninista-PC-ML-, que a su vez fundaría luego el EPL, portador de la estrategia de la guerra popular prolongada (GONZÁLEZ, 2014).

Este partido no se consideraba una disidencia del partido oficial sino la continuación del mismo, con una nueva orientación. Agrupaba sujetos diversos entre quienes habían sido expulsados del partido oficial -como Pedro Vásquez Rendón- junto a otros pequeños grupos que tenían un origen en el Movimiento Obrero Estudiantil Campesino-MOEC-, en la Juventud Comunista, en el Movimiento Revolucionario Liberal -MRL- y en el Partido de la Revolución Socialista -PRS-, con Pedro León Arboleda, Francisco Garnica, y también viejos guerrilleros de los años cincuenta, como Carlos Aníbal Cacua, Julio Guerra y Jesús María Álzate. A este grupo se le unieron militantes comunistas formados en Cuba, como Francisco Caraballo, Libardo Mora y David Borrás. La nueva agrupación, que también se empezó a conocer como el Partido Comunista Chino, se organizó en 160 cuadros en todo el país (PARDO, 2004).

Las zonas en donde se organizaron estos cuadros fueron el Magdalena Medio santandereano, el centro del Valle del Cauca, el nororiente de Antioquia y el sur de Córdoba. En esta primera etapa tendrían su mayor avance en este último territorio. El Alto Sinú y el Alto San Jorge permitieron una inmediata proyección a Córdoba, Urabá y el Bajo Cauca, zonas que progresivamente dejaron de ser selvas inexploradas para convertirse en haciendas ganaderas y agrícolas (VILlaRRAGA, 1994). En el sur de Córdoba se asentó el grupo guerrillero y quiso establecer un autogobierno campesino a través de lo que llamaban Juntas Patrióticas, y en febrero de 1967 se constituyeron en Ejército de Liberación Nacional, destacamento Francisco Garnica. Este grupo fue rápidamente repelido por el Ejército Nacional, 
puesto que entre mayo y agosto de 1968 inició una operación en el Alto Sinú y después de tres meses logró desmantelar a la mayoría de rebeldes. En estas operaciones murieron por lo menos tres docenas de combatientes, entre los que se encontraba Pedro Vásquez Rendón (PARDO, 2004). Estos primeros grupos del EPL no tuvieron mayor capacidad de ampliar su influencia en el territorio nacional. Escisiones internas y la presión de las Fuerzas Militares acosaron a los incipientes grupos.

En la década de los sesenta y setenta el desarrollo de las guerrillas en el territorio nacional no fue notorio, puesto que estas estaban marginadas a zonas periféricas y al carácter incipiente de dichas organizaciones. De igual manera, tal marginalidad de la guerra se explica en buena medida por la política reformista del Frente Nacional: "Pese a las restricciones democráticas sobre las cuales se erigió, la alianza bipartidista habilitó canales institucionales para la movilización social y para ampliar la competencia política en los ámbitos local y regional que serían de válvula de escape a los radicalismos" (Grupo de Memoria Histórica, 2013).

Ahora bien, el fin del Frente Nacional supuso una nueva fase de ascenso de las guerrillas. La presidencia de Julio César Turbay Ayala (1978-1982) supuso un despliegue represivo del Gobierno y de los mandos militares, con el apoyo de los gremios - particularmente la Federación de Cafeteros y la Sociedad de Agricultores de Colombia-contra la protesta social urbana. Un decrecimiento de la economía fue el detonante del descontento popular, que se va a agudizar con el paro cívico de diciembre de 1977. Todo este malestar supuso de nuevo un avance de los grupos guerrilleros. Las FARC, por ejemplo, a finales de la década de los setenta contaban con nueve frentes guerrilleros. Había dejado atrás una estrategia defensiva para trasegar hacia una ofensiva, lo que llevó a la multiplicación de sus frentes a 30, en 1986 (Grupo de Memoria Histórica, 2013).

Durante el gobierno de Belisario Betancur (1982-1986), el EPL se va a encontrar en medio de la voluntad de diálogo del Gobierno y su dificultad para trazar un camino de paz. Betancur, a diferencia de la posición de Turbay que había descartado la solución política al conflicto, reconoció oficialmente que había causas estructurales de la violencia, y en consecuencia inició el Plan Nacional de Rehabilitación-PNR-, en las zonas de conflicto e introdujo en el sistema político algunos cambios. 
En principio el EPL se rehusó a un entendimiento con el Gobierno, pues veía la voluntad de paz de Betancur como una trampa hacia el fascismo. A pesar de esto, la Segunda Conferencia Nacional del EPL adoptó una posición que tendría efectos posteriores: por primera vez se aceptó la posibilidad de un diálogo directo con el Gobierno Nacional y, al mismo tiempo, se trabajaría en unión con los otros grupos guerrilleros: el ELN, las FARC y el M-19. Sin embargo, los diálogos y el cese al fuego, declarado en agosto de 1984, fueron cesados al año siguiente en la Tercera Conferencia Nacional de Combatientes del EPL. Se criticaba en este encuentro el incumplimiento de la apertura democrática. A la par, el EPL registró un aumento considerable del número de combatientes. El desarrollo mayor fue en Urabá y Córdoba. Un menor crecimiento se dio en los frentes de Risaralda, sur del Cesar, Norte de Santander y Putumayo. La respuesta del Gobierno fue una ofensiva militar especialmente en Córdoba, Sucre y Catatumbo (VILlarRaGA, 1994).

Especial atención se debe tener a la presencia del EPL en el Urabá, puesto que para este tiempo se convirtió en una fuerza decisiva. Esta región reúne condiciones del conflicto social bastante particulares y diferentes a las de otras zonas del país. Se trata de un territorio de reciente colonización y de rápido desarrollo agroindustrial. El EPL ha tenido una fuerte influencia en esta región desde su fundación, además con su brazo político el PC-ML logró articular un fuerte apoyo de los sindicatos de trabajadores de las bananeras durante la década de los ochenta (VillarRaGA, 1994).

Bajo el gobierno de Virgilio Barco (1986-1990), el EPL aparecía fortalecido al tener una presencia con apoyo popular en la región de Urabá y Córdoba, además de realizar actividades conjuntas, en lo que se llamó la Coordinadora Nacional Guerrillera que reunía los principales grupos guerrilleros existentes en el país (VILLARRAGA, 1994). El país y su clase política estaban reacios a continuar la iniciativa de paz del gobierno de Betancur. La toma del Palacio de Justicia por parte del M-19 y la retoma del mismo, por parte del Ejército, en noviembre de 1985, fue un decisivo escollo para el proceso de paz. Además, el asesinato sistemático de militantes de la Unión Patriótica llevó a la ruptura definitiva de la tregua en 1987. La política de paz de Barco, de esta manera, aparecía fuertemente limitada. 
Por eso, dicho gobierno adoptó un modelo despolitizado, institucionalizado y tecnocrático de la paz, centrado en la inversión de obras de infraestructura que buscaban romper el aislamiento geográfico y la marginación de las regiones afectadas por el conflicto armado, por medio del Plan Nacional de Rehabilitación-PNR-. Quitarle base social a la guerrilla sin descuidar el fortalecimiento de la presencia del Ejército y la Policía fueron dos ejes de la estrategia de Barco para enfrentar el conflicto armado (GRUPO DE MEMORIA HISTÓRICA, 2013).

La mirada territorial vino acompañada de la aplicación de reformas democráticas que posibilitaron la descentralización política y administrativa. En particular, se dio la primera elección popular de alcaldes en 1988. Además, vino el reconocimiento de fuerzas políticas de izquierda dentro de la plaza pública, como la Unión Patriótica. Estos avances políticos tuvieron su correlato en las guerrillas, las cuales promovieron la protesta social con el fin de desestabilizar el orden político y con ello generar un levantamiento popular. Es en este contexto que las tensiones entre el Gobierno Nacional y las Fuerzas Pública se avivaron, a la par que se multiplicaron los grupos de autodefensas, que mutaron rápidamente en grupos paramilitares. De esta manera, "la guerrilla se militarizó y la Fuerza Pública criminalizó a la izquierda democrática y en general a la movilización social expresada en huelgas, paros cívicos y otras formas de manifestación. Así, unos y otros diluyeron las fronteras entre combatientes y civiles, entre luchas sociales y acciones insurgentes" (Grupo DE Memoria Histórica, 2013).

A principios de 1989, el EPL planteó desarrollar un movimiento político de oposición que combinara la guerra revolucionaria con la acción política, en el que se aglutinaran los más vastos sectores. Había la idea de desarrollar iniciativas de diálogo sin renunciar a mantener un plan militar. Además, se tomó la decisión de consolidar la retaguardia teniendo en cuenta consideraciones geográficas y militares. Para ello se escogió el histórico noroeste, desde el que se tenía acceso a la Costa Atlántica, Córdoba, Urabá y Antioquia. A este lugar se trasladó una sección de la Escuela Nacional de Combatientes y se estableció el Frente Jairo de Jesús Calvo, bajo la dirección de Tobías Lopera. Se concentró en el mismo lugar la Compañía de Fuerzas Especiales Ernesto Rojas. Se construyó un campamento de retaguardia en Puerto Libertador, Río San 
Jorge arriba, donde también se instaló el Mando Central del EPL. A la par de esta concentración de fuerzas, se fortaleció el trabajo miliciano y se empezaron a realizar desplazamientos del EPL hacia las otras zonas (VillarRaga, 1994).

El Mayor General Luis Ignacio Barón Casas, en uso de buen retiro y segundo comandante de la Fuerza Aérea Colombiana (2015-2018), quién participó como piloto en muchas de las operaciones que realizó la FAC en varias regiones del país, recuerda que la región de Urabá era una de las más violentas en las décadas de los ochenta y noventa, por su posición estratégica, el abandono del Estado, la presencia de grupos guerrilleros, las Autodefensas Unidas de Colombia y los carteles del narcotráfico:

“El departamento de Córdoba, uno de los que integraban la región en
1989, estaba infestado por el EPL. El Estado entonces decide crear
las Brigadas Móviles y reconquistar a Córdoba. Se crea la Primera
Brigada Móvil y nos dicen: 'vamos a llegar en una gran operación
militar, hay que desplegar al EPL de la región porque tienen azotados
a los ganaderos, toda la región ganadera está quebrada, y luego entra
el Plan Nacional de Rehabilitación-PNR- y todo lo que ha pasado el
Estado lo suple'. Todo esto después de una guerra en la que la guerrilla
había entrado a arrasar casi que, con el territorio y los pueblos; en los
campos la pobreza y la desolación eran terribles" (ENTREVISTA MAYOR
GENERAL LUIS IGNACIO BARÓN CASAS).

Las actividades militares durante este año fueron escasas, sin embargo no pasaron desapercibidas para el Ejército Nacional, el cual detuvo a varios integrantes del EPL que eran facilitadores en los diálogos con el Gobierno. Además, hacia el mes de noviembre de 1989, el Ejército desencadenó una ofensiva contra el campamento de retaguardia en Puerto Libertador con tropas helitransportadas. Este ataque fue particularmente negativo, puesto que este campamento era el lugar de contacto para las posibles negociaciones entre el EPL y el Gobierno. Esto supuso un alejamiento entre las partes por un breve tiempo. Hacia enero de 1990 el EPL propuso al Gobierno un cese de fuego bilateral, el cual venía estimulado por cierto cansancio con la guerra tanto del grupo guerrillero como de su brazo político el PC-ML, además la coyuntura internacional mostraba el quiebre del proyecto soviético (VILLARRAGA, 1994). 


\section{Operación Mutatá (UrabÁ, nOVIEMBre de 1989)}

\section{Preparación de la Operación:}

"Entre junio y noviembre de 1989, la cuadrilla Francisco Garnica Narváez del EPL realizó actividades de extorsión y narcotráfico en el área general de los municipios de Tierra Alta, Santafé de Ralito, Puerto Anchica, Montelíbano, Puerto Libertador, Buenavista y Planeta Rica, con aproximadamente 200 hombres armados. El departamento de inteligencia del Ejército, con base en informaciones, ubicó el campamento del Comando Nacional del EPL en Puerto Mutatá, sobre el Río San Jorge, y el 3 de noviembre de 1989, la Brigada 11 planeó una operación con los batallones de Infantería Junín y Cartagena, y el batallón de Contraguerrillas No. 11, con agregación de cuatro helicópteros UH.60, tres UH-1H, un artillado mediano y el apoyo directo de fuego de un AC-47 y aviones A-37" (CENTRO DE Estudios HistóRICOS DEL EJÉRCITO, 2014).

\section{Campo de combate:}

"La subregión de Urabá, ubicada al noroccidente de Colombia, en realidad no corresponde a una subdivisión administrativa de carácter nacional, sino más bien a una división geográfica derivada de una serie de acontecimientos históricos que unen de alguna forma al Gran Urabá, cuyo territorio se adentra en el de tres departamentos colombianos: Antioquia, Chocó y Córdoba. La zona es rica en especies de fauna y flora y en fuentes fluviales y minerales y cuenta con una excepcional conexión marítima y fluvial hacia el exterior. La subregión se asienta en torno al golfo de Urabá, que limita con Panamá y hace parte del llamado Chocó Biogeográfico, zona supremamente biodiversa, la cual disfruta de buenas condiciones geológicas y climáticas. Urabá está compuesto por 18 municipios: 11 de ellos en Antioquia (Arboletes, San Juan de Urabá, San Pedro de Urabá y Necoclí, al norte; Apartadó, Carepa, Chigorodó y Turbo, al centro; y Mutatá, Murindó y Vigía del Fuerte, al sur); 5 en Chocó (Acandí, Carmen del Darién, Riosucio, Unguía y Capurganá) y 2 en Córdoba (Tierralta y Valencia)". (Nieto y Otros, 2015).

Mutatá, denominada la Puerta de oro del Urabá está localizada en la parte noroccidental del departamento de Antioquia, tiene una extensión de 1.119,00 $\mathrm{km}^{2}$ y una población actual de 12.607 habitantes(DANE, 2018). Limita al norte con los municipios de Turbo y Chigorodó, al sur con el municipio de Dabeiba, 
por el este con el departamento de Córdoba y el municipio de Ituango, y por el oeste con el departamento del Chocó (ver Imagen No. 1).
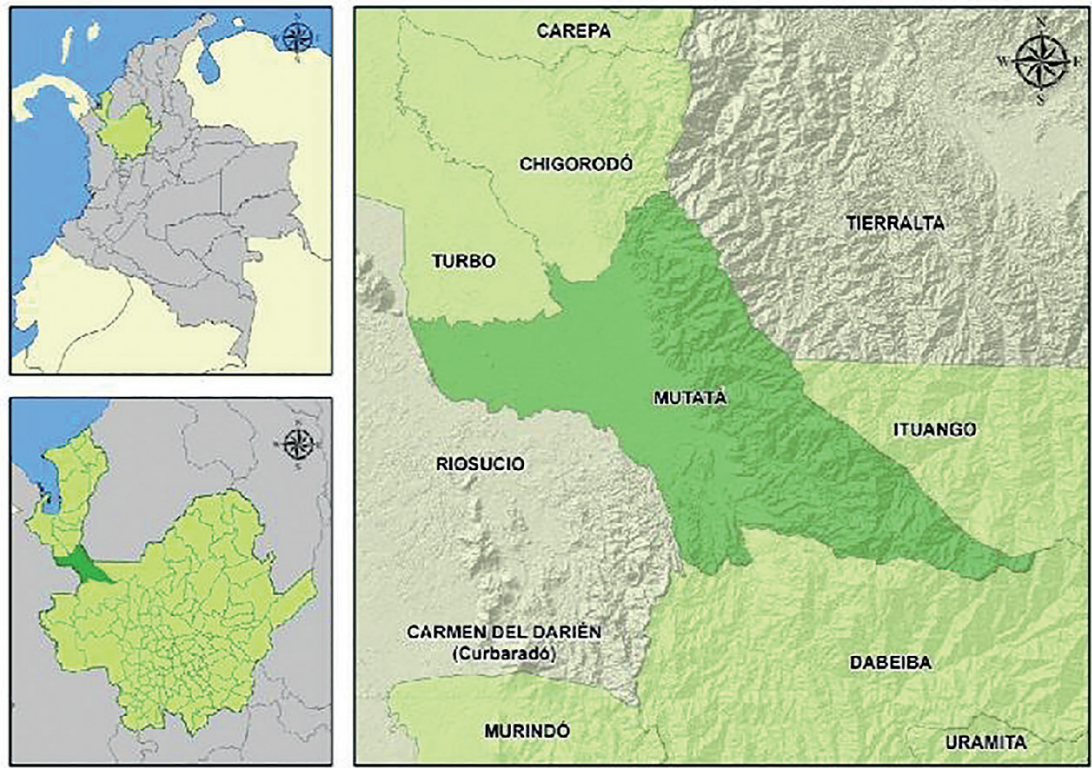

Imagen No. 1. Ubicación de Mutatá. Consejo Municipal para la Gestión de Riesgos de Desastres. 2017.

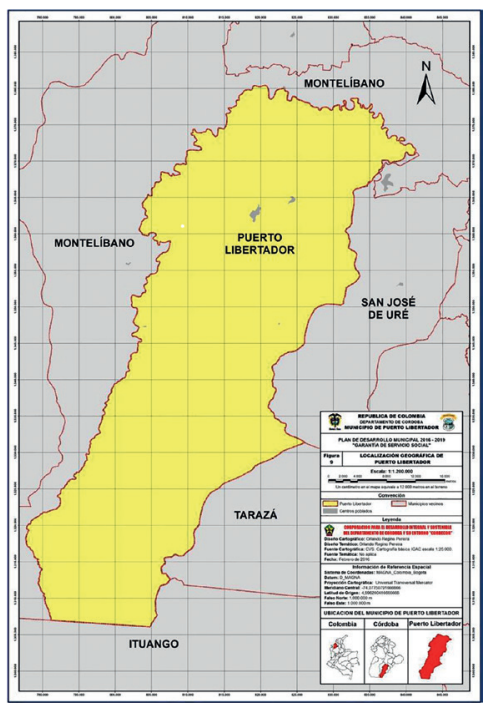

Imagen No. 2. Ubicación de Puerto Libertador. Plan de Desarrollo Puerto Libertador 2016-2019. 
El municipio de Puerto Libertador está localizado en el suroriente del departamento de Córdoba. Tiene una extensión de $2.062 \mathrm{~km}^{2}$ y una población actual de 35.362 habitantes (DANE, 2018). Limita al norte con el Río San Jorge, que lo separa del municipio de Montelíbano, al sur con el departamento de Antioquia, por el este con las quebradas Cristalina, San Antonio y Uré, que lo separan del municipio de Montelíbano, al oeste con el río San Jorge, que lo separa del municipio de Montelíbano (Imagen No. 2).

El Mayor General Luis Ignacio Barón Casas señala que estos dos municipios ubicados en los departamentos de Antioquia y Córdoba son la entrada al Nudo de Paramillo, donde estaban también asentados el Bloque Noroccidental de las FARC y parte del ELN, y donde estas guerrillas diseñaron corredores de movilidad muy definidos, para comunicarse con todo el país, e introducir las armas y sacar la droga (ENTREVISTA MAYOR General Luis Ignacio Barón CaSas) (Imagen No. 3).

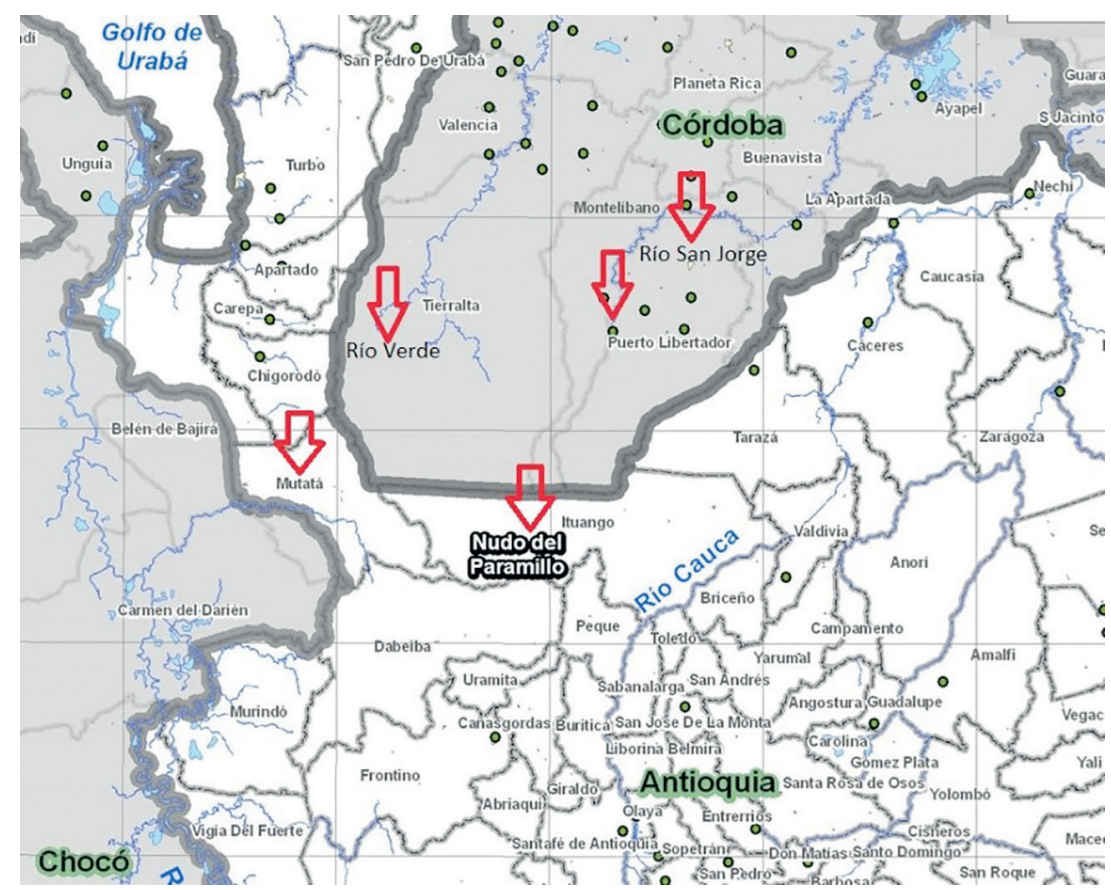

Imagen No. 3. Presencia del EPL en Antioquia y Córdoba. DANE, SIMCI / OCHA DEVINFO, OCHA OCHA, NASA. Elaboración propia. 
El Mayor General Barón describe la región de Urabá como una región que no tiene una identidad propia, ya que se conformó por campesinos que fueron desplazados por los grandes gamonales, quienes les usurparon sus tierras en Córdoba. Menciona que el desplazamiento es una de las grandes tragedias que ha vivido el país, y que si se va un poco más atrás a la historia de la conformación de Urabá, esta tiene cuatro características: la presencia de la comunidad indígena de los Kunas - estaban sobre el río Atrato llegando al Golfo de Urabá-; los asentamientos sobre el río Atrato de los negros que habían escapado de la esclavitud-quienes eran muy fuertes en la explotación del oro-; la llegada de los campesinos desplazados de Córdoba; los indígenas Chilapos -migrantes del departamento de Córdoba que arribaron al Urabá-.

Sobre la colonización de la región del Urabá la profesora Patricia Nieto (2015) afirma que esta:

"Propició condiciones que marcaron el sino de la subregión en pocos años. Sus procesos de poblamiento se produjeron de forma más o menos paralela a la expansión de grupos armados en el país: durante la década de los sesenta a la subregión comenzaron a llegar grupos de campesinos que acabaron produciendo un cambio radical en las dinámicas propias de una zona fronteriza, donde hasta entonces primaban los pequeños cultivos, la pesca artesanal y otras prácticas de bajo calibre. Para la época, sin embargo, comienza a producirse un vuelco hacia la economía agroindustrial, en parte como consecuencia de dinámicas nacionales (donde la incipiente economía de mercado colombiana comenzaba a integrarse a un sistema internacional de intercambios comerciales), en parte porque pequeños y medianos capitales comenzaron a fijarse en las potencialidades de los ecosistemas que rodeaban el golfo de Urabá. La subregión comenzó además un proceso de urbanización acelerado que a día de hoy no se detiene".

La convivencia entre esos procesos de poblamiento y la expansión de las guerrillas entre la década de los sesenta y comienzos de la década de los noventa produjo no sólo expresiones violentas de diversa índole, sino sobre todo dinámicas de organización política bastante fructíferas. La colonización campesina llevó a Urabá segmentos de población particularmente desfavorecidos, desplazados por la violencia o por sus carencias, que llevaron sus problemáticas a la zona: así, limitaciones para el acceso a la tierra (que ya entonces comenzaban a apropiarse grandes y medianas agroindustrias), exclusión política y económica, puesto que la 
subregión, a pesar de haberse integrado a la economía nacional a través de la formalización de sus prácticas económicas, siguió estando apartada del resto del país incluso materialmente (las carreteras de acceso a Urabá son pocas y están en precarias condiciones incluso a hoy), e incursión de grupos armados (con todas las complejidades que esto entraña), dieron forma a dinámicas de organización política y armada particularmente complejas (NiETo ET. Al., 2015).

El Mayor General Luis Ignacio Barón Casas recuerda que esa gran operación que se hizo en Córdoba generó que el EPL saliera de ese departamento por la zona de río verde, que es el límite entre Córdoba y Urabá, y se replegara en la zona de Mutatá, que es parte del Alto San Jorge, y en la zona del Nudo de Paramillo. En Mutatá se habían aposentado guerrilleros del EPL, y allí es donde se forma la Coordinadora Nacional Simón Bolívar desde 1987, que estaba integrada por las FARC, el ELN, el EPL, el M-19, el Partido Revolucionario de los Trabajadores y el Movimiento Armado Quintín Lame, y que realizó la toma de Saiza (Tierralta, Córdoba). Esa era la zona campamentaria del EPL. Allí se realizaron varias operaciones, una denominada Héroes de Urabá, otra Héroes de Dabeiba y todas eran para tratar de repeler esos grupos armados al margen de la ley de ese territorio (ver Imagen No. 3).

El Mayor General Barón continúa explicando que el Plan Nacional de Rehabilitación-PNR- nunca llegó a la región:

Nosotros entramos con la Brigada Móvil y realizamos unas operaciones muy fuertes en Córdoba y digamos que todo el EPL se repliega hacia Urabá. Se creó una Jefatura Militar Especial en Urabá y Córdoba por la violencia tan grande que había en esas regiones, y esos Jefes Militares, que yo los transporté, ya que duré un año en esa Jefatura Militar, fueron los Generales Fernando Gómez Barros, Jesús Armando Arias Cabrales, Jorge Hernán Guzmán y Adolfo Clavijo.

Mutatá fue una Operación en respuesta a una toma de la guerrilla a un Comando de Policía. Yo recuerdo haber sacado unos policías muertos de allá, cuando asaltaron una Unidad Militar y se robaron un mortero. Se hizo una operación especial con ataque aéreo. Esa fue una zona de constantes operaciones porque estaban esos reductos del EPL, las FARC, las Autodefensas. 
La importancia de estas operaciones que realizó la Brigada Móvil es que participaban cerca de 1.500 o 2.000 hombres que eran soldados profesionales, es decir, soldados que ya han tenido formación militar. Cuando hubo tanta presión militar en esta región es que el EPL empieza a hacer un Acuerdo de paz con el Gobierno para entrar a la Constituyente de 1991 y trabajar como partido político en la misma.

Estos soldados profesionales son los que llegan a la región de Córdoba para liberarla, y desde la FAC llegamos con los helicópteros para apoyar todas las operaciones, para apoyar la movilidad a los soldados, con los UH-60 Black Hawk. Nosotros íbamos en los artillados guiando; asegurábamos el área y llegaban los helicópteros y hacían asaltos sobre campamentos, sobre zonas, sobre puntos avanzados en el terreno; esa era la movilidad que procuraban los helicópteros. Para eso nos mandaron a nosotros en estas operaciones, para movilidad y apoyo de fuego directo a las unidades militares que estaban en Córdoba (ENTREVISTA MAYOR General Luis Ignacio Barón Casas).

\section{Combate}

Durante la Operación Mutatá, realizada conjuntamente por la Brigada No. 11 del Ejército Nacional, el Batallón de Infantería No. 33 “Batallón Junín”, el Batallón de Infantería No. 6 "Batallón Cartagena” y el Batallón de Contraguerrilas No. 11 "Cacique Coyará", que se llevó a cabo entre el 12 y el 15 de noviembre de 1989, en la vereda Puerto Mutatá, ubicada en el corregimiento Juán José, municipio de Puerto Libertador, en el departamento de Córdoba, la Fuerza Aérea Colombiana atacó la Cuadrilla Francisco Garnica Narváez del Ejército Popular de Liberación.

"El 12 de noviembre, a las 06:15 horas, el campamento fue bombardeado por aviones A-37, y con el apoyo del AC-47 el batallón contraguerrillas No. 11 desembarcó en el objetivo. El UH-1H FAC4101 se accidentó sobre el objetivo y fue atacado, pero los soldados, con apoyo de las otras unidades, lograron desembarcar contrarrestando la acción de los guerrilleros, y mediante fuego y maniobra, en un fuerte combate, dan de baja 18 guerrilleros. Los helicópteros fueron impactados en aquel intenso combate mientras se trataba de apoyar a la aeronave en tierra. Una vez asegurado el objetivo, continuaron las operaciones de registro, presentándose la muerte de dos guerrilleros más en los días posteriores al bombardeo. El 16 de noviembre de 1989, el helicóptero caído fue 
sacado del área junto con las tropas del BCG 11" (CENTRO DE Estudios HISTÓRICOS DEL EJÉRCITO, 2014).

El periódico El Tiempo reportó diariamente los acontecimientos y las bajas que se presentaron. En su edición del 12 de noviembre registró la muerte de cinco guerrilleros del Ejército Popular de Liberación, durante enfrentamientos con tropas del Batallón Junín pertenecientes a la Brigada No. 11. Dicho enfrentamiento se presentó en el caso urbano de la Rica, en el corregimiento de Puerto Libertador (EL TIEMPO, 1989).

En la edición del 13 de noviembre de 1989, el mismo diario reportó un recrudecimiento de la ola de violencia en el país, en el cual se reportó un saldo de 28 muertos, entre los que se incluían cinco miembros de las Fuerzas Armadas, cuatro miembros del EPL, en Apartadó, Antioquia, y otros cinco miembros del EPL, en Puerto Libertador, Córdoba, estos últimos abatidos por el Batallón Junín. (EL TIEMPO, 1989).

El 14 de noviembre se informó que 18 guerrilleros del EPL murieron en Córdoba en un enfrentamiento con tropas del Ejército, en una operación militar que se desarrolló entre las 6:30 a.m. y las 10:30 a.m., en donde tropas del Batallón Junín atacaron a los guerrilleros en una zona selvática, "en el corregimiento de San José, municipio de Puerto Libertador (EL TIEMPO, 1989).

El 15 de noviembre reportó enfrentamientos en cuatro departamentos del país: Bolívar, Boyacá, Córdoba y Huila, y la intendencia de Casanare. "En Córdoba expertos de los batallones Junín, Nariño y Cartagena, apoyados por helicópteros armados, atacaron el campamento "Francisco Garnica Narváez" del EPL. La sede insurgente estaba localizada en la vereda Puerto Mutatá, cerca de Puerto libertador". Durante esta operación "guerrilleros del Ejército Popular de Liberación (EPL) averiaron de consideración un helicóptero tipo UH60-Halcón Negro (Black Hawk) de matrícula $\mathrm{FAC} 4101^{3}$, que se encontraba en operaciones de orden público en apoyo de las tropas del Ejército (...), en el momento del accidente, el aparato realizaba el transporte de un grupo militar especializado en la lucha antiguerrillera (...) El aparato con cerca de 15 soldados a bordo,

La información reportada por el periódico El Tiempo no coincide con la registrada por el Centro de Estudios Históricos del Ejército, en donde se especifica que la aeronave averiada era un helicóptero UH-1H 4101, el cual se accidentó sobre el objetivo y fue atacado. 
volaba a baja altura cuando fue alcanzado por una granada disparada por un guerrillero". (EL TIEMPO, 1989).

De otra parte, el periódico El Espectador, en su edición del 15 de noviembre, realizó un reporte general de la operación, donde detallaba la zona, y reportaba que luego de las operaciones militares adelantadas en los departamentos de Antioquia y Córdoba, 28 guerrilleros pertenecientes al Ejército Popular de Liberación y al Ejército de Liberación Nacional fueron dados de baja, la incautación de armas y material bélico, en Puerto Libertador, donde se presentó un saldo de 18 guerrilleros del EPL muertos.

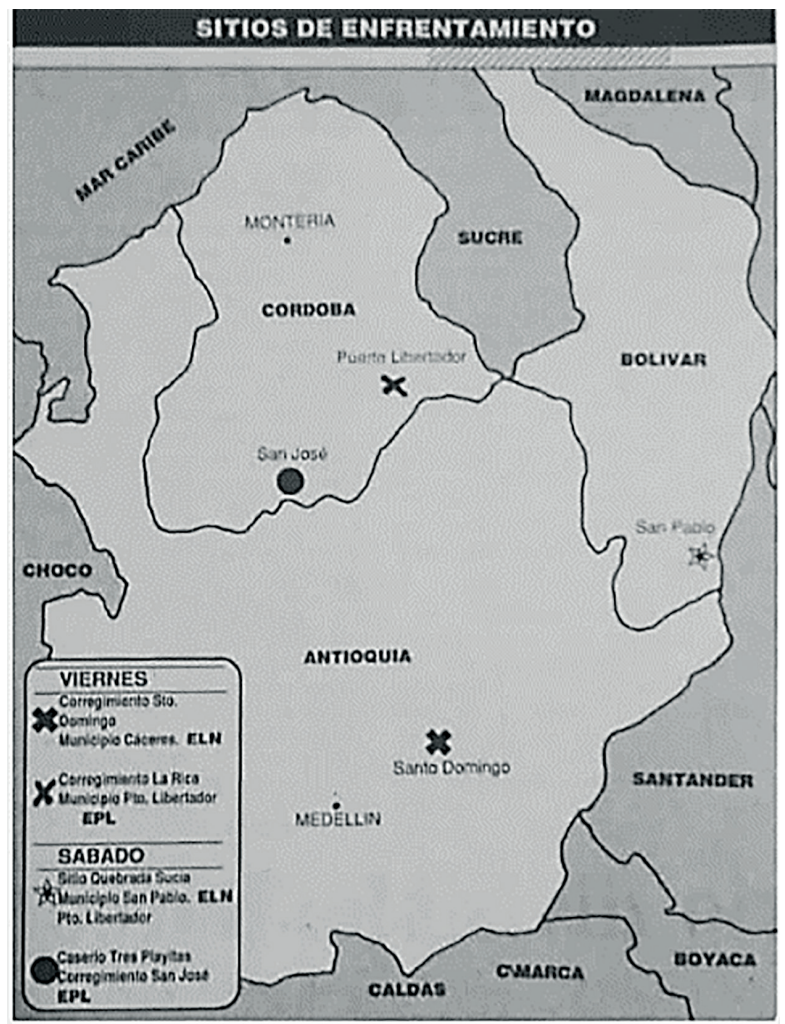

Imagen No. 4. Enfrentamientos entre la Fuerza Pública y grupos guerrilleros en Córdoba y Antioquia. El Espectador, 1989.

El ministro de Defensa, Óscar Botero Restrepo, informó a la ciudadanía en un comunicado de prensa emitido por su cartera que "tropas de la primera y segunda divisiones del Ejército con apoyo de la 
Armada, la Fuerza Aérea y la Policía Nacional, obtuvieron en los últimos días excelentes resultados en su empeño de restablecer el orden público y garantizar la seguridad de las gentes que habitan en áreas afectadas por la delincuencia organizada (...) en Puerto Libertador (Córd.) tropas de la Décima Primera Brigada en operaciones contra la guarida de la cuadrilla Francisco Gárnica del autodenominado EPL dieron de baja y causaron heridas un número indeterminado de antisociales, de los cuales han sido hallados hasta el momento dieciocho cadáveres". El comunicado resaltaba que "el alto espíritu combativo y la preparación de las unidades, aunados a la efectiva cooperación de la comunidad permitirá a las Fuerzas Armadas no solamente la vigencia de la ley y el restablecimiento del orden público, sino neutralizar los alevosos intentos de la subversión. De esta manera los colombianos iremos recuperando paso a paso la seguridad y la paz que necesitamos". (EL EsPECTADOR, 1989).

Se informó que "dos tripulantes del helicóptero UH-60 de la FAC que también cayó a tierra, en desarrollo de hechos que tuvieron ocurrencia en cercanías del río San Jorge, departamento de Córdoba, resultaron ilesos pese a que la aeronave sufrió destrozos importantes" (El EsPeCTADOR, 1989).

Estos combates se prolongaron hasta el 15 de noviembre y dejaron cómo resultado:

- Guerrilleros del EPL muertos en combate: 20

- Guerrilleros del EPL capturados: 06

- Armas largas incautadas: 02

- Escopetas incautadas: 02

- Ametralladora incautada: 01

- Armas cortas incautadas: 03

- Munición de varios calibres incautados: 4.000

- Uniformes de policía: 50 (CENTRO DE Estudios Históricos DEL EJÉRCITO).

El Mayor General Luis Ignacio Barón Casas recuerda que luego de esta operación se podía decir que quedó libre Córdoba: 
"Uno podía ver la alegría también en todos esos pueblitos como Valencia, Planeta Rica, Montelíbano, que son las regiones del Alto San Jorge, donde antes estaban los campamentos del EPL, porque supuestamente habían quedado tranquilas. Sin embargo, en esta región nunca llegó el PNR, no hubo Estado en esas regiones. Entonces regresaron los grupos armados al margen de la ley. Ya no era el EPL, sino que entraron las FARC y allí es que nacen las verdaderas Autodefensas de Urabá y Córdoba, porque empezaron las FARC a golpear a todos los campesinos, a invadir y a robarse las tierras; entonces ahora sí nacen las Autodefensas de Fidel Castaño (que antes en 1979 eran incipientes y por venganza a la muerte de su papá). Ya en esta época están metidas en el narcotráfico; entraron primero apoyadas por grupos de grandes ganaderos de la región, pero claro, qué hacían ellos si nosotros fuimos y les llevamos paz, y después, todo aquel que apoyó al Ejercito, las guerrillas los asesinaron, a ellos y a sus familias" (ENTREVISTA MAYOR General Luis Ignacio Barón CASAS).

De acuerdo con el Mayor General Barón si el PNR se hubiera materializado, Colombia sería diferente;

\begin{abstract}
"si realmente lo que nos prometieron a nosotros, que era que entrabamos con las Brigadas Móviles y después entraba el PNR y el Estado (escuelas, colegios, vías, etc.), si eso hubiera pasado, el fenómeno de la violencia en Córdoba se hubiera acabado, y ese modelo de Córdoba se habría replicado en otras partes del país, y seguramente que Colombia no habría vivido la violencia tan grande que vivimos desde los años ochenta hasta hoy, o hasta hace unos años. Esta operación fue exitosa; el grupo más grande del EPL (salvo las disidencias que todavía existen) entró en este proceso de paz con el M-19 y el Quintín Lame, y desaparecieron esos grupos de la violencia colombiana" (ENTREVISTA MAYOR GeNERAL Luis IGNACIO BARÓN CASAS).
\end{abstract}

Luego de esta operación, el Mayor General Barón en el año 1990 continúo operando helicópteros y realizó la Operación Colombia en el Meta, denominada Operación Casa Verde para atacar la base del Estado Mayor de las FARC-EP.

\author{
PROCESO DE PAZ CON EL EPL, DESMOVILIZACIÓN Y \\ CONSTITUYENTE DE 1991
}

Son múltiples los factores que condujeron a la dejación de armas del EPL. El Estado colombiano, entre los cuatrienios de Barco y de 
César Gaviria sostuvo un doble discurso: por una parte, de ampliación de la democracia -que aparecía como un reclamo de los distintos grupos guerrilleros y movimientos sociales- y, por otra, de despliegue militar en los centros más fuertes del EPL, como el Urabá y el sur del departamento de Córdoba. El EPL también compartía la ambigüedad del establecimiento político que se apreciaba en la extensión del accionar militar y a su vez de una aparente voluntad de diálogo.

El estado del EPL a finales de los años ochenta y principios de los noventa era el de una guerrilla que venía en un proceso de franco crecimiento, puesto que contaba con 18 frentes activos, entre rurales y urbanos, y una presencia significativa en cinco regiones del país: Córdoba y Urabá, Occidente de Antioquia, el Eje Cafetero, Nororiente, Sierra Nevada de Santa Marta y otras partes de la Costa Atlántica, y Putumayo y la Bota Caucana (VILLARRAGA, 2009). Sin embargo, la coyuntura internacional y nacional llevó al EPL a replantearse el ejercicio armado y pensarse como una guerrilla que quería pasar a la legalidad como grupo político.

En particular, se tiene la desaparición del socialismo real en Europa, con los hechos significativos de la caída del muro de Berlín en 1989 y la disolución de la Unión Soviética en 1992 (BASTA YA, 2013). Internamente, fue muy importante el proceso de paz exitoso con el M-19, el cual trajo consigo un viento favorable a la democratización de las instituciones políticas, impulsando de esta manera los diálogos con otros grupos guerrilleros. Al respecto afirmaba el consejero de paz de los gobiernos de Barco y Gaviria, Jesús Antonio Villarraga:

"El 8 de marzo de 1990, se produjo la desmovilización del M-19, como el primero de una serie de procesos de desmovilización que se consignaron por los analistas, con la denominación de "paz parcelada", y que cubrieron todo el periodo de Gaviria. Más allá de las vicisitudes de las negociaciones, de la manera como el M-19 irrumpió en la vida política y de las implicaciones de su participación en el gobierno, aquí habrá que señalarse la significación del modelo de negociación del M-19, que va a permear no solamente los acuerdos con otras organizaciones en proceso de desmovilización, sino también a crear enormes distancias respecto de las posibles negociaciones con la Coordinadora Guerrillera Simón Bolívar" (VILlaRRAGA 2009).

Subraya Villarraga que las negociaciones con grupos guerrilleros como el EPL, el Quintín Lame y el PRT tendrían un nuevo marco referencial: 
en primer lugar, la Convocatoria de la Asamblea Nacional Constituyente, que fue un elemento decisivo en el proceso mismo de las negociaciones; en segundo lugar, las partes van a aprovechar las lecciones que dejaron los acuerdos de desmovilización con el M-19, especialmente, en los términos del contenido de los acuerdos de desmovilización y reinserción; y finalmente, una tendencia, por parte del nuevo Gobierno a flexibilizar en alguna medida el esquema de negociación (VILLARRAGA, 2009).

Dentro del EPL el paso decisivo hacia los diálogos con el Gobierno tuvo que ver con una comprensión de la coyuntura nacional. De esta manera, el grupo guerrillero dejaba atrás el sectarismo y se abrió, especialmente, a la influencia de sus cuadros legales, los cuales "sustentaron la necesidad de abrir una fase de distención política, criticaron la subestimación de la lucha política y llamaron a profundizar el contenido real de una salida política" (Villarraga, 1994). En este sentido, la convocatoria a la Asamblea Nacional Constituyente en 1990 fue determinante para abrir paso a las negociaciones del proceso de paz y dejación de armas con las guerrillas:

"el 12 de mayo los medios de comunicación difundieron una declaración suscrita por los comandantes del EPL y los mandos de frente - excepto Francisco Caraballo, quien objetó el borrador y presentó una contrapropuesta- que planteaba cómo en el camino de la guerra no era ya posible una salida a la crisis del país. Este pronunciamiento de los mandos del EPL consideraba viable un acuerdo con base en un cambio de institucionalidad, que hiciera posible la apertura democrática" (VILlarRaga 1994).

El 15 de febrero de 1991 el EPL y el Gobierno firmaron el Acuerdo Final de Paz, y el 1 de marzo de 1991 se realizó el proceso de entrega de armas, entregadas por cerca de 2.000 combatientes (2.149 en todo el país), luego de la expedición de un decreto de Indulto por parte del Gobierno, para que pudieran reinsertarse a la vida civil y convertirse en un partido político, que luego pasó a llamarse Esperanza, Paz y Libertad. Sobre este punto, afirma Álvaro Villarraga, antiguo miembro del EPL, que además de los combatientes se desmovilizaron 6.400 cuadros y militantes clandestinos. "Eran 18 frentes rurales que hacían presencia en casi todos los departamentos. Nos concentramos en diez zonas que se redujeron a seis. Quedó una pequeña disidencia, pero el grueso de nuestros militantes entra a la vida política nacional" (EL EsPECTADOR, 2016). 
La participación de antiguos miembros del EPL en la Constituyente fue importante, puesto que dos integrantes - Jaime Fajardo y Darío Mejía-, un dirigente del Frente Popular -Germán Toro-y un dirigente de la Juventud Revolucionaria y destacado líder de la Séptima Papeleta -Fabio Villa- ingresaron en calidad de constituyentes; los dos primeros en virtud del Acuerdo de paz, y los dos segundos, elegidos por votación en el contexto de la Alianza Democrática que se conformó al momento. Ellos expresaron la voz tanto del paso de la insurgencia a la legalidad como de la convergencia con el influjo político y social que rodeaba al EPL (Centro Nacional de Memoria Histórica, 2016)

\section{CONCLUSIONES}

Los procesos de poblamiento y colonización de la región de Urabá y la posterior aparición y asentamiento de grupos guerrilleros, autodefensas y narcotraficantes en la zona ponen de relieve la importancia de la presencia del Estado en las regiones más apartadas del país, y de la Fuerza Pública para garantizar la seguridad de las poblaciones y el respeto de los derechos de la ciudadanía. También, como un factor determinante para superar el conflicto social y el conflicto armado, en donde es clave tener el control sobre los territorios y la implementación de políticas económicas y sociales que permitan mejorar las condiciones de vida y de acceso a educación, salud, vivienda y servicios básicos de la población en general.

A lo largo del conflicto armado colombiano se ha observado el uso legítimo de la fuerza por parte del Estado para garantizar la seguridad pública, el cumplimiento de la ley y la defensa y la salvaguarda de los territorios, en donde prevalece el respeto por los Derechos Humanos y el Derecho Internacional Humanitario, y el bien común. Algunas de las operaciones adelantadas muestran la adopción de una salida militar al conflicto interno, pero también de la mano de una clara disposición de los gobiernos para finalizar la guerra en Colombia, y brindar las garantías en los procesos de desmovilización y reinserción a la vida civil de los grupos armados.

La firma del Acuerdo de paz con el EPL representa un referente en el proceso de desmovilización, reinserción a la vida civil y participación política de grupos armados al margen de la ley en Colombia. Dicho 
Acuerdo de paz no hubiera sido posible sin la intervención de las Fuerzas Militares y la Fuerza Aérea Colombiana en los asentamientos guerrilleros y en territorios que como Urabá y Córdoba fueron de los más golpeados por la violencia a lo largo de nuestra historia republicana y, en especial, en las décadas de los ochenta y noventa, estas intervenciones militares permitieron el debilitamiento del EPL. La Operación denominada Mutatá fue claramente uno de los golpes más certeros por parte de las Fuerzas Militares al núcleo de concentración principal del EPL. Luego de esta operación se puede observar que se empiezan a dar las condiciones políticas, como una disposición de diálogo y desmovilización por parte de este grupo guerrillero.

Vale la pena resaltar la coordinación y tecnología utilizadas por las Fuerzas Militares colombianas, en particular la Fuerza Aérea, para desarticular al EPL en la región de Urabá y el departamento de Córdoba. Si bien el Estado colombiano, desde mediados de la década de 1980, sostuvo una voluntad de negociación con los grupos alzados en armas, ejerció el supremo deber del uso de la fuerza en condiciones en las cuales el orden público fue desestabilizado por las guerrillas en sus diversas versiones y grupos.

\section{REFERENCIAS}

Alcaldía Municipal de Puerto Libertador. Nuestro Municipio. Recuperado de: http://www.puertolibertador-cordoba.gov.co/ municipio/nuestro-municipio

Centro de Estudios Históricos del Ejército. (2014). Históricas Operaciones Militares. Bogotá, Centro de Estudios Históricos del Ejército.

Centro Nacional de Memoria Histórica. (2016). Tomas y ataques guerrilleros (1965-2013). Bogotá, CNMH - IEPRI.

CentroNacionaldeMemoriaHistóRica.(2016).Epl25añosconstruyendo paz. Recuperado de: http://www.centrodememoriahistorica.gov.co/ noticias/noticias-cmh/epl-25-anos-construyendopaz

Centro Nacional de Memoria Histórica(2014). Guerrillay Población Civil, Trayectoria de las FARC 1949-2013. Bogotá, Tercera Edición. CNMH. 
Consejo Municipal para la gestión de riesgos de desastres-CMGRD. (2017). Estrategia municipal para la respuesta a emergencias y desastres. Recuperado de: https://repositorio.gestiondelriesgo.gov.co/bitstream/ handle/20.500.11762/27913/Mutata.pdf?sequence $=2$ \&isAllowed $=y$

DANE (2018). Censo Nacional de Población y Vivienda-CNPV 2018 -Dane. Recuperado de: https://www.dane.gov.co > informaciontecnica > CNPV-2018-VIHOPE-v2

DANE, mod SIMCI, OCHA DEVINFO mod OCHA OCHA, NASA. Mapa de Antioquia. Recuperado de: https://www.gifex.com/ fullsize/2011-08-19-14353/Mapa_de_Antioquia.html.

DANE (1995). La defensa nacional y las fuerzas militares, Documento CONPES 282. Bogotá. MinDefensa-Consejería Defensa y Seguridad-DNP:UJS. Recuperado de: https://colaboracion.dnp.gov. co/CDT/Conpes/Econ\%C3\%B3micos/2824.pdf

Duque, E. (2016). Plan de Desarrollo Municipal 2016 - 2019. “Garantía de servicio social". Recuperado de: https://puertolibertadorcordoba. micolombiadigital.gov.co/sites/puertolibertadorcordoba/content/ files/000002/87_pdm_parte_estratgica_puerto_libertador_v32tomo-1.pdf

GonzÁLez, F. (2014). Poder y Violencia en Colombia, Bogotá, OdecofiCinep.

Grupo de Memoria Histórica. (2013). ¡Basta ya! Colombia: memorias de guerra y dignidad. Bogotá, Centro Nacional de Memoria Histórica.

Municipios de Colombia. Recuperado de: https://www.municipio. com.co/municipio-mutata.html y https://www.municipio.com.co/ municipio-puerto-libertador.html

NieTo, P. y Otros (2015). Hacemos Memoria. Contexto histórico y social del departamento de Antioquia, subregiones: Urabá y Oriente. Medellín. Medellín, Universidad de Antioquia.

OrTIZ, J. (2016). Plan de Desarrollo 2016 - 2019, Mutatá con educación y desarrollo rural. Recuperado de: https://mutataantioquia. micolombiadigital.gov.co/sites/mutataantioquia/content/ files/000003/112_pdm-20162019-mutata-26-de-mayo-de-2016.pdf 
PARdo, R. (2004) La historia de las guerras. Bogotá, Ediciones B, Colombia S.A.

SÁNCHEZ, G. "Guerra y política en la sociedad colombiana”. Análisis Político, No. 11. (SEP/DIC 1990). Bogotá, Instituto de Estudios Políticos y Relaciones Internacionales IEPRI, Universidad Nacional de Colombia.

Trejos, L. (2013). Aproximaciones a la actividad internacional de una organización insurgente colombiana El Ejército Popular de Liberación (EPL). De China a Cuba vía Albania. Barranquilla, Investigación y Desarrollo Vol. 21, No 2.

Villarraga, Á. (2017). Acuerdos de paz entre el estado y las guerrillas. Corporación Viva la Ciudadanía, Edición 531 - Semana del 24 de Febrero al 2 de Marzo de 2017. Recuperado de:http://viva.org.co/ cajavirtual/svc0531/pdfs/Articulo056_531.pdf.

Villarraga, Á. (2015). Acuerdos de paz y finalización histórica del conflicto armado. Fundación Cultura Democrática. Publicado en: Revista Derecho y Realidad, Vol. 13 Núm. 26, julio - Diciembre de 2015. Recuperado de:file://C:/Users/USUARIO/Downloads/7842Texto\%20del\%20art\%C3\%ADculo-20879-1-10-20180309\%20(1).pdf.

Villarraga, Á. (2015). Biblioteca de la paz 1980-2013. Los procesos de paz en Colombia, 1982-2014. Bogotá, Fundación Cultura Democrática. Recuperado de: http://biblioteca.ucp.edu.co/Descargas/ core/documentos/2.pdf.

Villarraga, Á. Compilador (2009). Acuerdos con EPL, PRT, MAQL y CRS, Diálogos con la CGSB. Bogotá, Fundación Cultura Democrática.

Villarraga, Á. y Plazas, N. (1994) Para reconstruir los sueños. Una historia del EPL. Santafé de Bogotá, Fondo Editorial para la Paz.

\section{FUENTES PRENSA}

El Espectador (2016).Memorias de paz con el Epl. Recuperado de: http://www.elespectador.com/noticias/paz/memorias-de-paz-el-eplarticulo-619502

El Espectador (1989a, noviembre 15). Abatidos 28 sediciosos en Córdoba y Antioquia (p. 12A; versión impresa). 
El Espectador (1989b, noviembre 15). Mueren 6 militares al caer un helicóptero en el Tolima (p. 12A; versión impresa).

El Tiempo (1989a, noviembre 12). Turbo (p. 4C; versión impresa).

El Tiempo (1989b, noviembre 13). Antioquia y Córdoba, los departamentos más ¡calientes! (p. Última B; versión impresa).

El Tiempo (1989c, noviembre 14). Muertos 18 guerrilleros en Córdoba (p. portada; versión impresa).

El Tiempo (1989d, noviembre 15). Ataques Guerrilleros en 4 departamentos (p. 3A; versión impresa).

El Tiempo (1989e, noviembre 15). A tierra dos helicópteros de la FAC (p. 3A; versión impresa).

ENTREVISTA

Mayor General Luis Ignacio Barón Casas, 18 de octubre de 2019. 